\title{
Onsite Quality Check for Installation of Prefabricated Wall Panels Using Laser Scanning
}

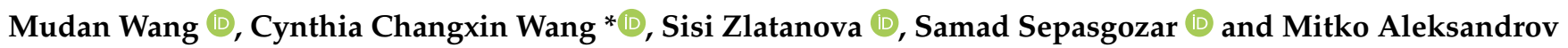 \\ School of Built Environment, The University of New South Wales, Sydney, NSW 2052, Australia; \\ mudan.wang@student.unsw.edu.au (M.W.); s.zlatanova@unsw.edu.au (S.Z.); Sepas@unsw.edu.au (S.S.); \\ mitko.aleksandrov@unsw.edu.au (M.A.) \\ * Correspondence: cynthia.wang@unsw.edu.au
}

Citation: Wang, M.; Wang, C.C.; Zlatanova, S.; Sepasgozar, S.; Aleksandrov, M. Onsite Quality Check for Installation of Prefabricated Wall Panels Using Laser Scanning. Buildings 2021, 11, 412. https:// doi.org/10.3390/buildings11090412

Academic Editor: Robert Amor

Received: 1 August 2021

Accepted: 11 September 2021

Published: 16 September 2021

Publisher's Note: MDPI stays neutral with regard to jurisdictional claims in published maps and institutional affiliations.

Copyright: (c) 2021 by the authors. Licensee MDPI, Basel, Switzerland. This article is an open access article distributed under the terms and conditions of the Creative Commons Attribution (CC BY) license (https:// creativecommons.org/licenses/by/ $4.0 /)$.
Abstract: Prefabricated construction has gained increasing popularity to meet the needs of rapid city development in recent years. Installation quality check is a critical task in prefabricated construction, and currently mostly still carried out manually, which is slow and ineffective. To provide an efficient and practical quality check method to replace the current manual method, this paper elaborates on an approach for checking prefabricated wall panels using laser scanning. The approach is validated in an actual case study. A common laser scanner BLK 360 is adopted to collect onsite 3D scenes after panel installation. The point clouds collected are co-roistered, classified, and segmented. Geometric parameters such as angles and distances allow for determining whether the installation meets the quality requirement. The outcome is compared with the quality check results using the conventional manual method. The results show that the panels, which need rectification, are correctly identified by the proposed approach. The major contribution of this study is determining the set of segmentation parameters to be adopted in similar quality check-up procedures. A practical and efficient quality check process is also proposed and can be readily implemented for certain prefabricated elements in many construction cases.

Keywords: prefabricated wall panel; installation quality check; laser scanning; 3D point cloud; segmentation; plane fitting

\section{Background}

In recent years, prefabricated construction is recognized as a more efficient construction method, and has a wide range of benefits in improving the industry's productivity, sustainability, quality, and health and safety [1-4]. In contrast to conventional construction, there are additional lifting and installation processes for prefabricated elements, which have direct impacts on the overall project quality [5,6]. For prefabricated construction projects, one of the most common and important procedures is to ensure that prefabricated wall panels (PWPs) are accurately installed.

The conventional installation and quality check procedures of PWPs are shown in Figure 1; there are six major steps, including lifting to position, installation, checking horizontal alignment and verticality during installation, and re-checking horizontal alignment and verticality after installation. Horizontal alignment is to install PWPs at the right position. The datum lines on the floor are used to locate the PWPs (Figure 1, step 3). Verticality check relates to the accuracy of vertical installation. A plumb line measuring tool is used to check if one PWP is accurately vertical (Figure 1, step 4). After installation of all PWPs, a re-check process for the whole floor is performed, which includes steps 5 and 6 in Figure 1. The re-check of horizontal alignment needs to check the relative positions of those neighboring PWPs that are supposed to be aligned. The re-check of verticality is to check the accuracy of verticality after installation based on a more accurate measuring tool. 


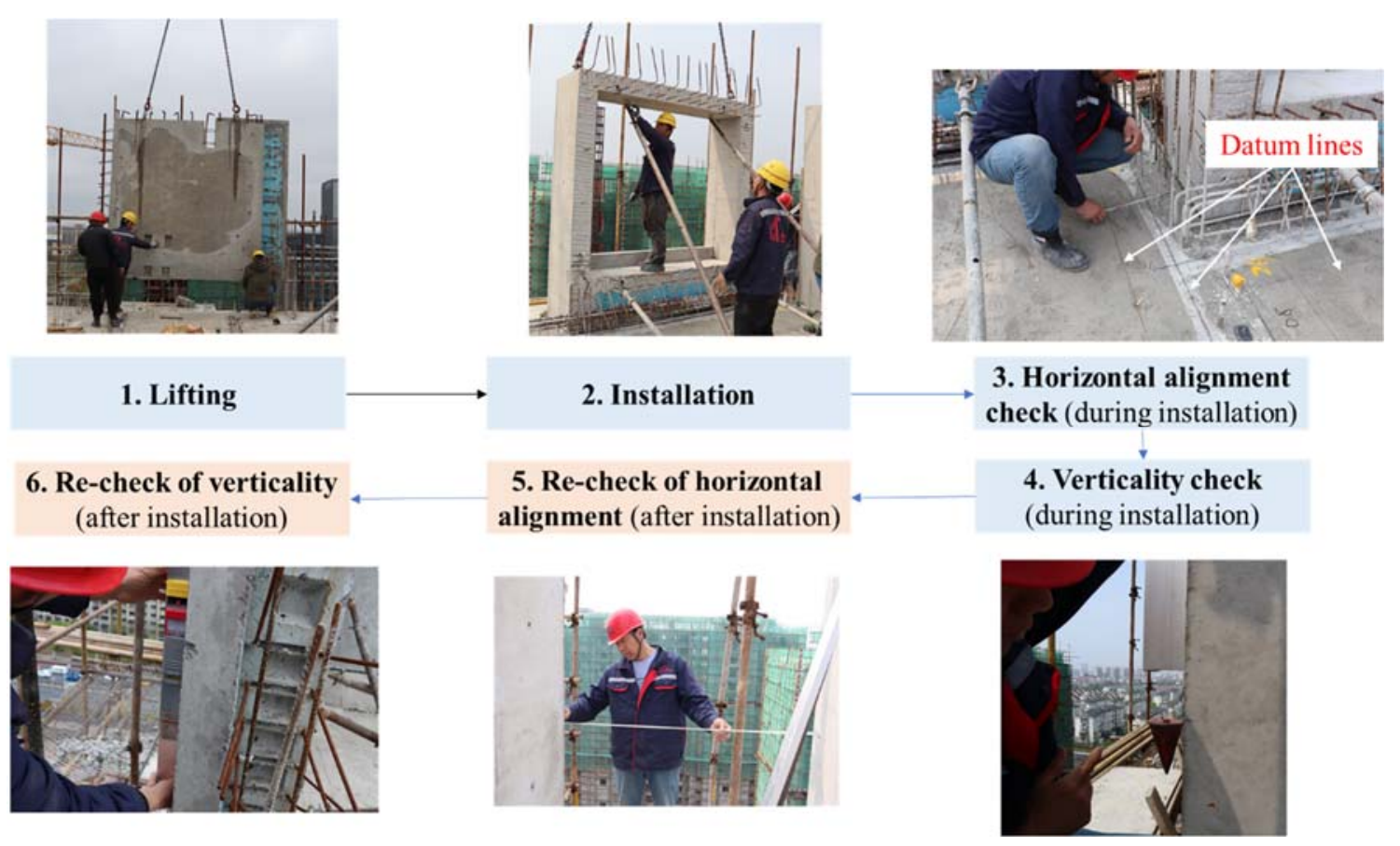

Figure 1. Installation and quality check procedures of PWPs on site.

The re-check process of steps 5 and 6 are referred as installation quality check (IQC) in this study. The IQC process is usually carried out manually on individual PWP one by one, which is very time consuming and labor intensive, especially for a project with a large number of prefabricated elements [3,7]. In such cases, a more efficient measurement method is required.

Laser scanning is a promising technology for quality check since it could collect high-density geometry data of objects accurately and objectively [1,8-10]. Some studies have proposed using laser scanning technology for quality check on surface defects and flatness [11], dimensions [12,13], and rebar assessment [14] of PWPs. Wang et al. [11] proposed a flatness quality assessment method on prefabricated concrete bridge deck panels. Wang et al. [15] designed quality assessment methods to automatically detect geometry irregularities of prefabricated elements. Liu et al. [16] carried out an automated geometric quality check of multiple precast concrete elements based on a laser scan point cloud. Other studies focused on quality check of indoor finished rooms, which are different from the construction site environment. For example, Wang et al. [17] proposed a house internal geometric quality check method to assess verticality, flatness, and other geometric properties of an existing building interior. However, applications of using laser scanning in IQC of prefabricated wall elements are still rare [1].

This paper presents a method for the quality check of PWPs after installation. The proposed method can be used to check a large number of installed PWPs (replacing steps 5 and 6 in Figure 1). It aims to achieve an efficient and practical IQC of PWPs using laser scanning. There are two major issues to be resolved. The first objective is to identify PWPs from laser scanning data based on point cloud segmentation and classification methods. The success of PWP identification relies on the effectiveness of the segmentation algorithm. The aim is determining suitable thresholds to be used in the segmentation per use-case. The second is making the overall procedure practical and effective, including scanner selection and measuring approach of horizontal alignment and verticality. The main purpose of the proposed method is to effectively identify the PWPs that need to be rectified using laser scanning data.

In the remainder of the paper, Section 2 reviews the previous studies on quality check of prefabricated elements, and point cloud segmentation and classification methods 
for laser scanning data. Section 3 presents the onsite quality check criteria and how the conventional checking method is carried out. Section 4 introduces the proposed framework of IQC method, including identification of PWPs and proposed procedures of IQC. Section 5 presents a case study using the method proposed in Section 4 to determine the suitable values of the parameters used in the segmentation and quality check process. It also compares the quality check results with the conventional manual check method, and discusses the effectiveness and practical value of the proposed method. Final conclusions are given in Section 6.

\section{Literature Review of Related Work}

\subsection{Quality Check of Prefabricated Elements}

In recent years, laser scanning technology has been widely introduced in construction industry. Laser scanning provides a way of digital information creation of physical properties, which is beneficial for the quality management of building construction in the long-term [18].

Due to the features of off-site construction, the quality check for PWP can be grouped in two categories, quality check in production process and after onsite installation $[19,20]$. Some studies used an as-design model as reference to detect variation in quality check. For example, Rausch et al. [21] compared three methods of using laser scanning data and BIM to carry out geometric accuracy analysis of prefabricated elements, including scan-to-BIM, scan-versus-BIM, and parametric BIM updating. Their research identified that scan-versus-BIM method produced the highest average accuracy. Rausch et al. [22] used laser scanning point cloud data and BIM to analyze the dimensional deviation of prefabricated elements, and obtained the spatial relationship between prefabricated components. Bosché and Guenet [23] used the scan-versus-BIM method to compute the flatness deviation, which is based on matching each point from point cloud with the corresponding element in the BIM model. Li et al. [24] aligned point cloud data with an as-designed BIM model and calculated the deviations of component surface based on the reference model points. Another approach is to conduct quality check based on laser scanning data without referring to the as-design model. Kim et al. [25] developed an edge and corner extraction technique using the vector-sum algorithm to extract geometric features of prefabricated panels from point cloud, and then evaluated the dimensional quality. The advantage of this approach is the higher efficiency and potential to be automated $[25,26]$.

Overall, most of these studies are on dimensional and flatness quality check in production process. Onsite assembly and installation quality check using laser scanning is rare; the only study retrieved from literature is the quality check of modular removable floodwall installation, which used the BIM model and laser scanning data to detect installation deviation [27]. The onsite installation of this study is focused on the assembly process of anchor plate, embedded parts, and fabricated modules. However, this method is not sufficiently practical, which needs a skilled BIM engineer to process the data, and needs to be more automated for practical onsite use. No other research reported in the literature carried out onsite installation quality check using laser scanning for prefabricated building elements. This paper aims to fill the research gap and develop a practical quality check method for onsite installation of prefabrication wall panels.

\subsection{Point Cloud Segmentation and Classification}

To conduct IQC of PWPs using laser scanning, each PWP needs to be identified in the point cloud data. Segmentation and classification of point cloud need to be performed. However, few studies have explored using appropriate segmentation and classification methods for the identification of PWPs from construction site data.

Segmentation is the process of grouping points into individual object surfaces or regions with similar features $[28,29]$. Previous studies on point cloud segmentation are more focused on detecting planar, circular, cylinder objects, and indoor reconstruction from 
point cloud data [30-32]. Since the wall panels are planar objects, the main concern of this study is plane segmentation methods. Plane segmentation is to obtain clusters on planar surfaces, and there are mainly four approaches for plane segmentation [29,33,34]:

1. Model fitting-based methods. The random sample consensus (RANSAC) algorithm and Hough transform belong to this category. The model fitting-based methods are robust segmenting for plane surfaces, especially datasets with high noise and outliers, whereas it could generate spurious and nonexistent planes, and it is used more for regular plane detection [35-37].

2. Region growing methods. Region growing is commonly used, as it is well known for its simplicity and relatively low computational cost for plane segmentation [30,38].

3. Clustering feature-based methods. Clustering feature-based methods are robust under noisy conditions, but they are computationally expensive and fail to segment complex situations [39,40].

4. Global energy optimization-based methods. The global energy optimization-based methods are also computation load consuming and always conducted after other segmentation methods. For example, Dong et al. [34] used the global energy optimizationbased method to obtain higher quality segmentation results after region growing process.

To provide a practical IQC method, the segmentation approach should be easy to use and efficient in consideration of computational expense and practicality. Among the different approaches, the region growing segmentation algorithm is commonly used due to these advantages and therefore it is adopted in this paper. However, it involves several segmentation parameters, which need to be properly determined. The main challenge is that there is no universal approach valid for all cases [29], and no investigation has been conducted on the segmentation of PWPs for construction site data.

Classification is the step that labels segments or group of points to specific classes based on different criteria, which is also called semantic segmentation or point labeling [28]. In construction projects, the as-design BIM models are usually used for classification of laser scanning data [15,16]. For example, Guo et al. [41] identified columns by automated matching laser scanning data to the as-design BIM model based on predefined control points. Bosché and Guenet [23] made the classification by matching laser scanning data with the as-design BIM model, based on the orthogonal distance and normal similarity between laser scanning points and object surface of BIM model. Some commercial software is also adopted for classification, such as as-built BIM model development from laser scanning data. Jung et al. [42] developed a semi-automated procedure for as-built BIM to reconstruct a 3D model in Leica Cyclone 8.0 software. Nguyen et al. [43] created an as-built BIM model by Revit from the point cloud. Sanhudo et al. [44] obtained geometric data from the laser scanning point cloud and created a BIM model using Revit. However, although these methods are largely successful, the way they used for classification failed to obtain the geometry properties of each element, so they could be inefficient for further specific quality check.

In summary, although much work has been done on segmentation and classification algorithms, the segmentation parameters need to be determined for each case. Currently, no research has focused on the PWPs and therefore there is a need to determine appropriate parameters for such cases. Moreover, checking the installation quality requires geometry properties of each PWP to be defined. This paper presents first results of the work on an efficient and practical method using laser scanning technology for onsite installation quality check of PWPs.

\section{Criteria of Installation Quality Check (IQC)}

There are several specifications on prefabricated construction projects in different countries, such as the US, Australia, and China. For example, in the US, according to the "Guide for Precast Concrete Wall Panels" reported by ACI Committee 533 [45], the installation tolerance of PWP is $\frac{1}{4}$ in $(6.35 \mathrm{~mm})$ for every $10 \mathrm{ft}(3.048 \mathrm{~m})$ of element height. In Australia, 
as required in "Reinforced Concrete Design (in accordance with AS 3600-2009)" [46], "AS3600-Concrete Structures" [47], and "Precast Concrete Handbook (Australian standards)" [48], tolerances of concrete structure deviation are about $\pm 10 \mathrm{~mm}$ to $\pm 20 \mathrm{~mm}$. In addition, the verticality deviation of walls must not exceed the greater of the specified dimension divided by 200 , or $10 \mathrm{~mm}$. Therefore, $10 \mathrm{~mm}$ can be regarded as the tolerance of prefabricated element installation for Australian projects. In China, there are several specifications for quality control of prefabricated concrete construction, such as national specifications such as the "Code for Construction and Acceptance of Concrete Structures" [49] and industry standards such as "Technical Specification for Prefabricated Concrete Structures" [50], as listed in Table 1.

Table 1. Dimensional tolerance deviation of prefabricated structures in China $[49,50]$.

\begin{tabular}{|c|c|c|c|}
\hline & Items & & $\begin{array}{c}\text { Tolerance Deviation } \\
(\mathrm{mm})\end{array}$ \\
\hline \multirow{3}{*}{$\begin{array}{c}\text { The verticality of } \\
\text { prefabricated } \\
\text { elements }\end{array}$} & \multirow{3}{*}{$\begin{array}{c}\text { The height of column } \\
\text { and wall panel after } \\
\text { erection }\end{array}$} & $<5 \mathrm{~m}$ & 5 \\
\hline & & $\geq 5 \mathrm{~m}$ and $<10 \mathrm{~m}$ & 10 \\
\hline & & $\geq 10 \mathrm{~m}$ & 20 \\
\hline \multirow{5}{*}{$\begin{array}{l}\text { Horizontal alignment } \\
\text { between contiguous } \\
\text { elements }\end{array}$} & \multicolumn{2}{|c|}{ Head face of the panel } & 5 \\
\hline & \multirow{2}{*}{$\begin{array}{l}\text { The bottom face of } \\
\text { beam and panel }\end{array}$} & Plastering & 5 \\
\hline & & Without plastering & 8 \\
\hline & \multirow{2}{*}{$\begin{array}{l}\text { Side face of column } \\
\text { and wall }\end{array}$} & Appeared & 5 \\
\hline & & Buried & 8 \\
\hline
\end{tabular}

This paper is based on the Chinese standards for PWP quality. If the height of PWP is less than $5 \mathrm{~m}$, the vertical deviation threshold $\left(T_{v d}\right)$ should be set as $5 \mathrm{~mm}$. The horizontal alignment deviation threshold $\left(T_{h d}\right)$ is set as $5 \mathrm{~mm}$ as well. However, these deviation thresholds can be easily adjusted according to the requirement of different countries; the proposed method can be generalized and adapted to most prefabricated projects worldwide.

The methods of calculating horizontal alignment deviation and verticality deviation are given in Figure 2. Deviation is the difference between installed PWP and designed requirements, such as the datum lines at the construction site. If the deviations are all lower than the thresholds, this PWP meets the quality requirement. Horizontal alignment checks are only conducted between the PWPs, which are designed to be parallel with the datum lines. The horizontal alignment deviation between PWPi and PWPj, $d_{i j}$, is shown in Figure 2a. The distances $d_{i}$ and $d_{j}$ between the bottom area of PWPi and PWPj with the datum line are measured. Then $d_{i j}$ of two neighboring PWPs can be calculated. Quality of verticality is checked by a specially made T-type measuring tool ( $2 \mathrm{~m}$ in length), as shown in Figure 2b. This tool is placed along at one side of PWP and the plumb line indicates the verticality. The horizontal distance between the plumb line and a midpoint, marked on the PWP, is the vertical deviation $\Delta l$. 


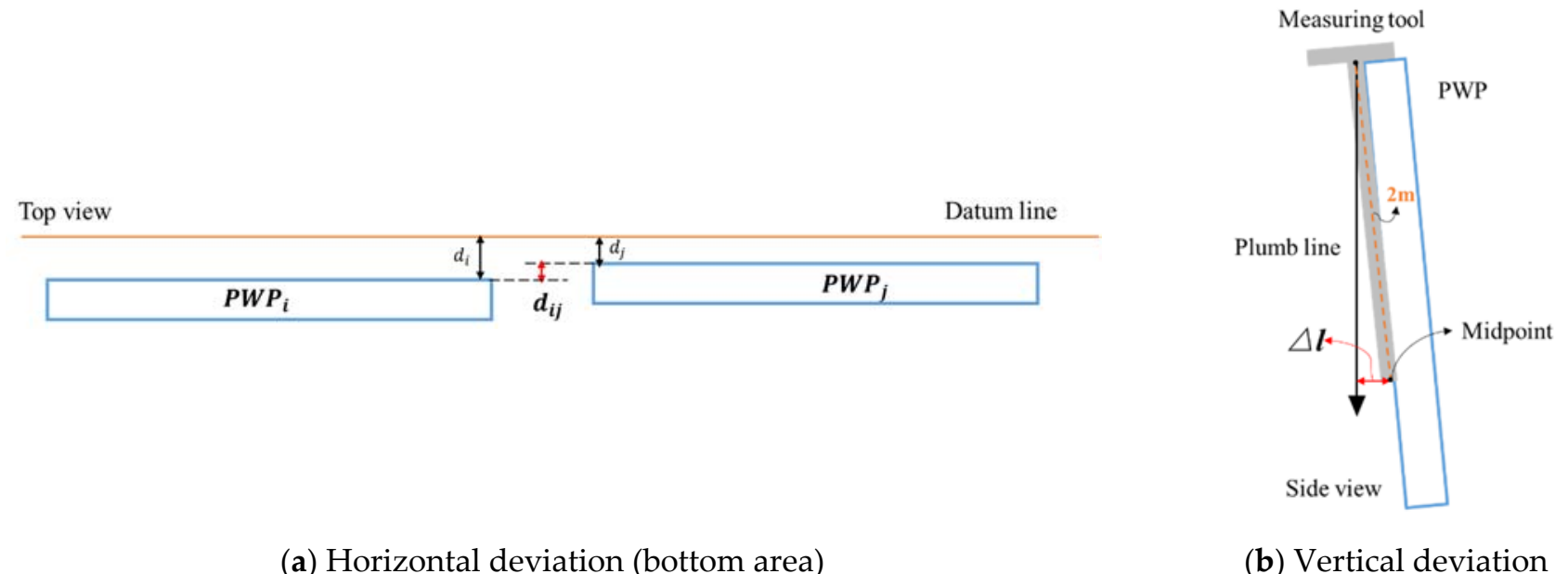

Figure 2. Conventional calculation method.

\section{Proposed IQC Method Using Laser Scanning}

\subsection{IQC Process}

The IQC process using laser scanning is shown in Figure 3. There are four phases, including data collection using laser scanning, PWP identification, quality check of horizontal alignment, and quality check of verticality.

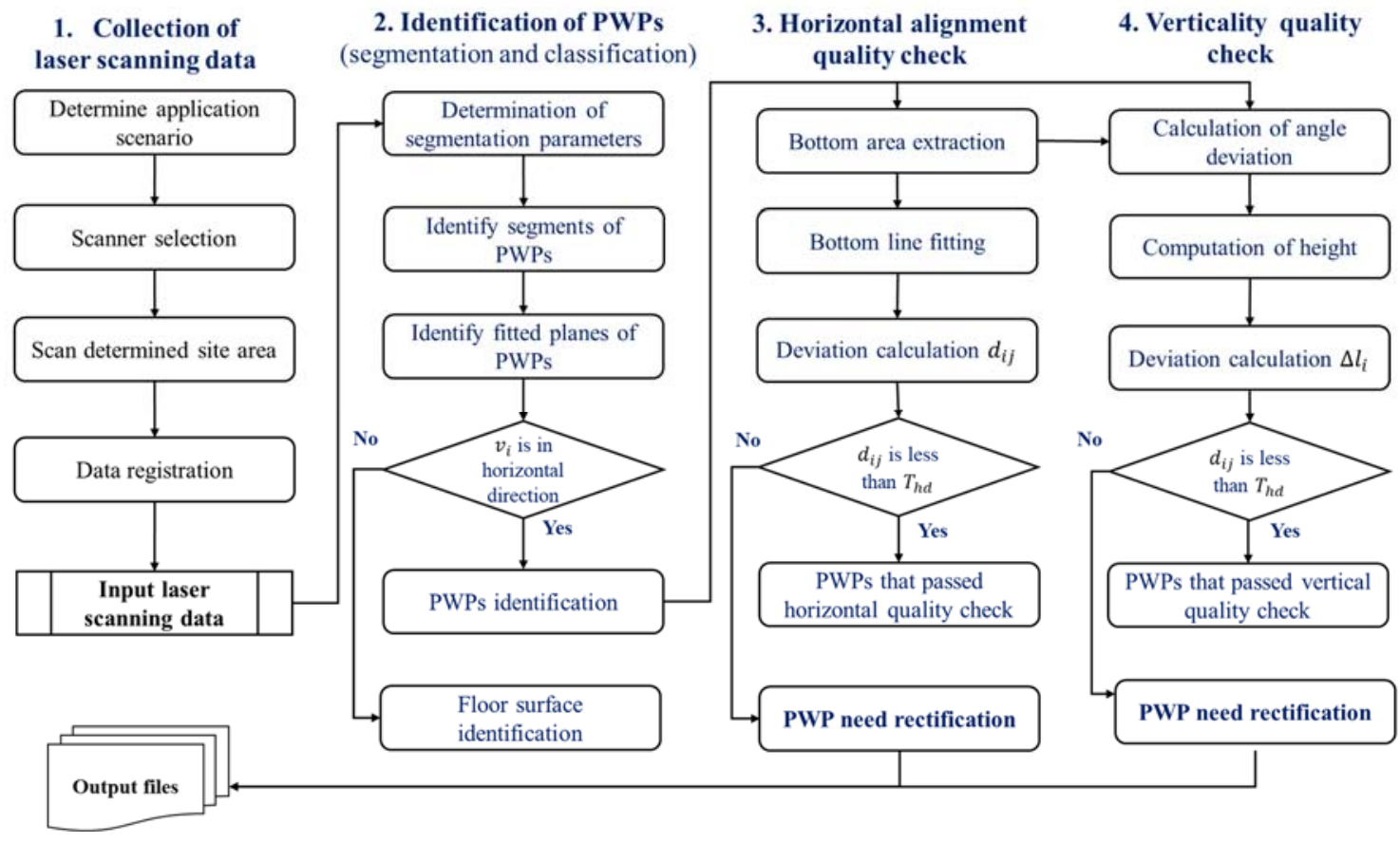

Figure 3. IQC process.

The first phase is to perform laser scanning. The proposed method should be practical to be used in onsite quality check. From the perspective of practical use, the scanner should be easily placed and moved at the cluttered construction site [44]. The time required for each scan should be short, as the construction site is dynamic and changes fast. In addition, the scanner needs to be easily accessible with low expense. From the view of technical consideration, the resolution, speed of scanning, scanning range, and accuracy are critical to obtain effective data at the construction site [51]. Considering from both practical and technical aspects, a commonly used laser scanner BLK 360 is adopted for this study, which 
is low cost, relatively small, light weight, and fast [52]. The scanner characteristics are shown in Table 2. The scanner with a scanning range of $60 \mathrm{~m}$ is sufficient to cover the site area in each scan. Each scan takes only $3 \mathrm{~min}$. The time to scan the site is after installation of all PWPs for one floor. The scanner should be located at a place where it can cover multiple PWPs. Usually, the distance from the scanner to the PWP may be approximately 2-4 $\mathrm{m}$ at the construction site, and so the scanning resolution and ranging accuracy could be higher than those provided parameters with distance of $10 \mathrm{~m}$ in Table 1 . The dense point cloud collected should be able to meet the requirements for the quality check, which will be further validated in Section 5 .

Table 2. Technical characteristics of the BLK 360 laser scanning device.

\begin{tabular}{cc}
\hline & Technical Characteristics \\
\hline Image resolution & $360^{\circ} \mathrm{HZ} \times 300^{\circ} \mathrm{V}(150 \mathrm{MP})$ spherical image \\
Scanning resolution & Every $10 \mathrm{~mm}$ in $\mathrm{HZ}$ and V (distance $10 \mathrm{~m})$ \\
Ranging accuracy & $4 \mathrm{~mm}$ every $10 \mathrm{~m} / 7 \mathrm{~mm}$ every $20 \mathrm{~m}$ \\
Speed of scanning & $360,000 / \mathrm{s}$ \\
Scanning range & $60 \mathrm{~m}$ \\
3D point accuracy & $6 \mathrm{~mm}$ every $10 \mathrm{~m} / 8 \mathrm{~mm}$ every $20 \mathrm{~m}$ \\
Scanning time & Less than $3 \mathrm{~min}($ full-dome scan) \\
Size & $165 \mathrm{~mm}$ tall $\times 100 \mathrm{~mm}$ in diameter \\
Weight & $1 \mathrm{~kg}$ \\
\hline
\end{tabular}

Co-registration is performed after laser scanning data collection, which is to combine data collected from different scans into one dataset [42,53]. Currently, there are many well-established software programs used for the data registration, such as Leica Cyclone 8.0 [42]. This process is commonly completed manually within the scanner's software. The required time of registration depends on the number of scans. If the construction site is large or consists of several separate rooms, there will be several scans for one floor scanning, as PWPs may occlude each other. The time spent for registration could be longer. If the construction site is more open, the scanning process could be very quick and efficient.

The second phase is to identify the PWPs within the point cloud (the details of the identification process are presented in Section 4.2). The site is normally cluttered with rebar, temporary supports, construction materials, etc., which are regarded as background points [15]. These background points need to be filtered first. As mentioned above, a region growing segmentation algorithm is adopted to detect the PWPs and floor surface and separate them from the background points. In the segmentation process, the most critical step is to determine the suitable values of segmentation parameters. After segmentation, a classification method using normal vector $v_{i}$ is used to identify the PWPs from the floor surface.

The third phase is to conduct the horizontal alignment quality check, as presented in Section 4.3. The PWPs that are unable to pass the quality check are identified.

The fourth phase is to conduct the verticality check. This phase is presented in Section 4.4. The check of horizontal alignment and verticality are carried out parallel in the proposed method.

Finally, PWPs that need either horizontal or vertical rectification are established.

\subsection{Identification of PWPS}

There are two steps for identification of PWPs: (1) segmentation based on the region growing algorithm and (2) plane fitting using the RANSAC algorithm.

\subsubsection{Region Growing Segmentation}

As the laser scanning data are unstructured points, the first step groups the points into segments with specific characteristics. As mentioned above, the segmentation is to identify PWPs and remove the background points. 
Region growing algorithm considers proximity of points and similarity of locally estimated surface features $[33,54]$. These features are planarity or roughness of the surfaces, which is computed by the normal vector and curvature [34,35]. First, all points are sorted by their curvature values, and the region grows from the point that has the minimum curvature value, which is regarded as a seed point. The seed point is in a flat area, so that growing of the region reduces the total processing [33]. Points, which are located at the vicinity of the seed point and have properties similar to the seed point, are grouped into the same cluster.

The challenge of segmentation is to find suitable values for the segmentation parameters. Inappropriate selection of values for those parameters might result in oversegmentation or under-segmentation problems [33]. Since there is no one-for-all solution to thresholding, the selection of suitable values of parameters is always done by trials and experiments [34]. There are different opinions on thresholding of region growing based on previous studies, mainly including the selection of $K S$ and $\theta_{S}$. The explanation of the five parameters and the suggested values that are reported in previous studies are listed, as follows [55-57]:

1. K search $(K S)-K S$ is the number of points used for the normal estimation of each point. The $\mathrm{k}$ nearest neighbors $(\mathrm{kNN})$ method is used to find neighboring points [34,58]. The selection of KS needs to consider the surface of PWP, point density, laser scanner type, and so on [55-57]. Some studies recommend using small $K S$, where the normal vector of each point is more representative of the local surface feature [54]. If $K S$ is large, normal estimation might ignore some details. For example, Xiao et al. [57] used $K S$ as 15 and 25. While many authors suggested using a larger $K S$ for better normal estimation, since a smaller $K S$ made the normal more susceptible to noise. For example, Deschaud and Goulette [59] proposed using 50 for KS. There is no agreement on determining the value of $K S$.

2. Number of neighbors (NN) - NN is the number of points neighboring the seed points for region growing. Both $K S$ and $N N$ used the kNN method to find neighboring points.

3. Minimum clusters $(M C)$ - this parameter sets the minimum number of points for a valid plane cluster, which means the clusters that have fewer points than this value are ignored.

4. Smoothness threshold $\theta_{S}(\mathrm{ST})$ - ST $\left(\theta_{S}\right)$ is the value to limit the angle difference of normal vectors between seed points and their neighboring points. The neighboring points with angle difference smaller than $\theta_{S}$ are regarded in the same cluster of seed points [34]. Dong et al. [34] pointed out two segmentation problems, over-segmented and under-segmented, which are caused by an inappropriate set of $\theta_{S}$. Smaller $\theta_{S}$ could result in over-segmented problem. Only closely similar points are merged, and many clusters are not detected under strict growing criteria. Conversely, larger $\theta_{S}$ cause under-segmentation, which allows some not-quite similar points to be grouped into the same cluster. Shao et al. [58] set $\theta_{S}$ as $10^{\circ}$ for the segmentation process, while Dong et al. [34] indicated $10^{\circ}$ is a relatively large value.

5. Curvature threshold $\gamma_{c}(\mathrm{CT})$ - the curvature constraint is used to test if a potential growing point can be added to a seed set.

There are few discussions on value selection of NN, MC, and CT $\left(\gamma_{c}\right)$. The selection of $\mathrm{NN}$ and $\mathrm{MC}$ need to consider the density of point cloud and the size of elements. The selection of CT $\left(\gamma_{c}\right)$ needs to consider the shape of the elements [56,57]. To provide a practical approach for onsite use, appropriate segmentation parameters for specific scenarios should be determined in advance. The segmentation and IQC procedure should be performed shortly after the laser scanning is completed.

\subsubsection{RANSAC and Classification}

The second step is to classify the PWPs and floor surface. A method using the normal vector $v_{i}$ to classify vertical and horizontal segments mentioned by Wang et al. [17] is 
adopted. The RANSAC algorithm is used to estimate the parameters of the best plane to the individual segments. The main advantage of the RANSAC algorithm is its robustness to compute a plane in the presence of a high percentage of outliers $(>50 \%)[24,60]$. The parameters needed for RANSAC are the minimum points, distance threshold, and iterations [61,62]. The minimum points adopt the value of $M C$ identified in region growing algorithm. Distance threshold is the maximum distance of point samples from the ideal plane, and the points are considered as an inlier [63]. The distance threshold is fixed to $6 \mathrm{~mm}$, which is the point cloud accuracy of the laser scanner. Iteration is the number that RANSAC will loop over. Higher iteration could make a more robust fitting result. For example, Imre and Hilton [64] applied RANSAC as 100 times. The iteration is set as 500 in this study, which is sufficient for this process. These parameters are predefined without further experiments. After RANSAC, the mathematical expression, unit normal vectors, and the contained points of the fitted planes are acquired. Therefore, based on the features of normal vector $v_{i}$, the floor surface and PWPs are classified. Each PWP is assigned a unique identifier (ID).

\subsection{Horizontal Alignment Check}

Quality check of horizontal alignment is focused on bottom edges of PWP, which is shown in red in Figure 4. The critical task is to obtain the bottom edge of each classified PWP. The first step is to extract points of the bottom area from the fitted plane. The height of each point is the distance from the point to the floor surface. Due to the impact of incomplete scanning and occlusions, the height $\left(T_{h}\right)$ of the bottom area is set at $0.2 \mathrm{~m}$ to obtain sufficient points. The $T_{h}$ needs to consider the shape of PWP and occlusions caused by supporting elements on the PWPs. The larger $T_{h}$ could ensure that more points can be obtained. If fewer points are selected, then the bottom edge estimation could be more easily influenced by noise and outliers. In addition, as some PWPs might have an opening in the bottom part, $0.2 \mathrm{~m}$ could ensure the sufficient points of the bottom part can be acquired. The height of points lower than $T_{h}$ are identified as bottom points of each fitted plane. Then the bottom points are projected to the $x-y$ plane. Finally, line fitting is performed through these projected points (Figure 4) using a linear regression algorithm [65].

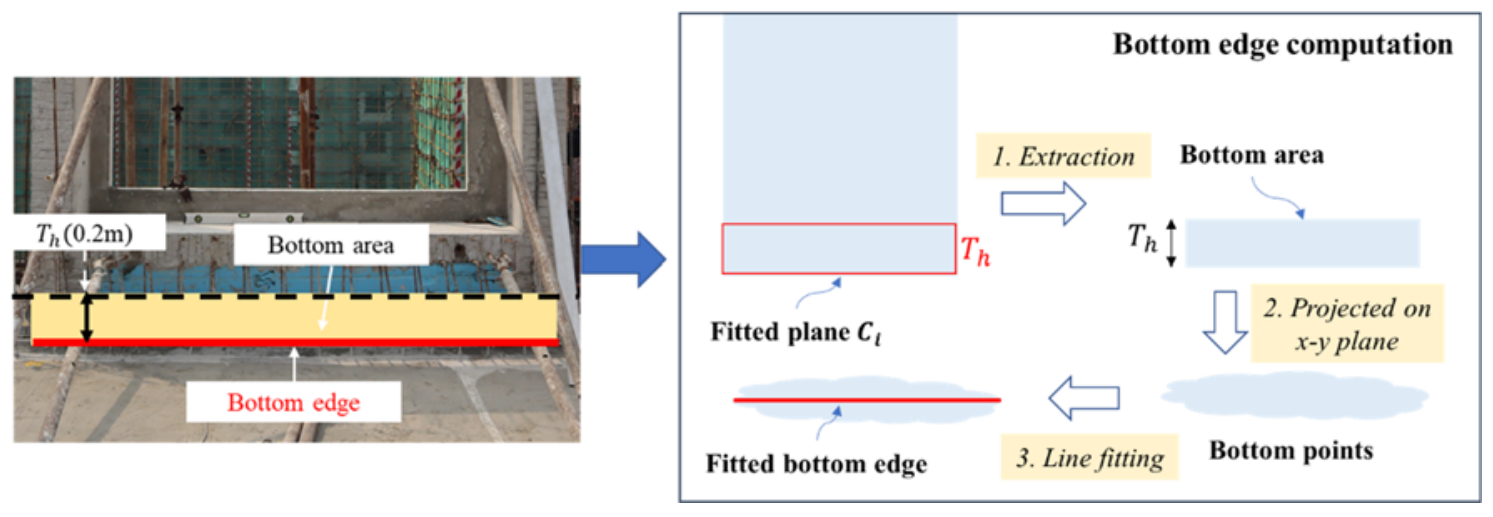

Figure 4. Bottom edge computation of PWP.

The second step is to compute horizontal alignment deviation $d_{i j}$. Horizontal alignment check needs to be conducted among the PWPs that will be installed at the same wall plane. These PWPs are determined based on design requirements and design drawings. First, the two panels should be parallel. If the two panels are not parallel with one another, then they are identified and need to be rectified, and there is no need to make a further check. Second, if the two panels are parallel, similar to the conventional method, the horizontal alignment deviation $d_{i j}$ is determined by the distance from the end point $P_{i}$ to the bottom edge of $\mathrm{PWP}_{\mathrm{i}}$, as shown in Figure 5 . 


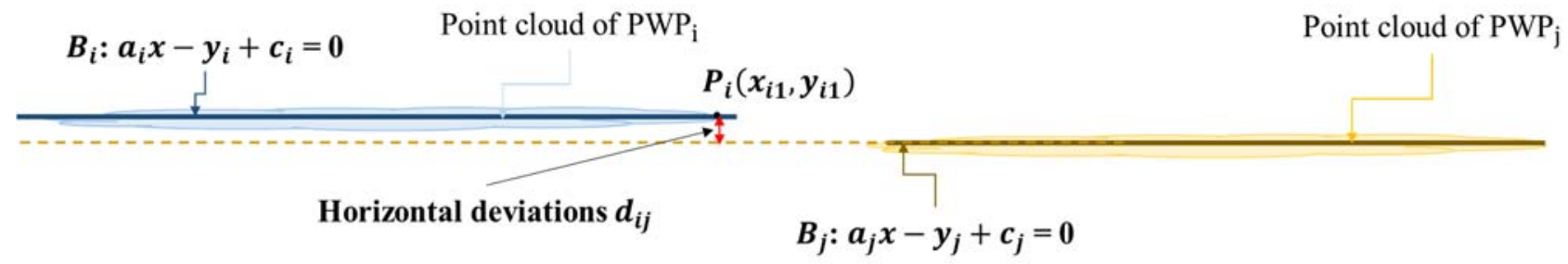

Figure 5. Horizontal alignment deviation computation.

According to the installation requirement in Section 3, the horizontal alignment deviation threshold $\left(T_{h d}\right)$ is $5 \mathrm{~mm}$. If the horizontal alignment deviation $d_{i j}$ is smaller than $T_{h d}$, it means that $\mathrm{PWP}_{\mathrm{i}}$ and $\mathrm{PWP}_{\mathrm{j}}$ pass the quality check. If it is larger than $T_{h d}$, then $\mathrm{PWP}_{i}$ and $\mathrm{PWP}_{j}$ need to be rectified.

\subsection{Verticality Check}

As introduced in Section 3, the vertical deviation is determined as $\Delta l$ (see Figure 2b). Unlike the conventional method, our approach adopts angle analysis (see Figure 6), but follows the same criteria of quality check as the manual check. Theoretically, our approach could be a better representation of verticality quality than the manual check. For example, verticality deviation $\Delta l$ from the top to the bottom area of PWP can be computed based on the point cloud, while the manual check uses only the tool to measure the deviation within $2 \mathrm{~m}$ range on the surface of the PWP.

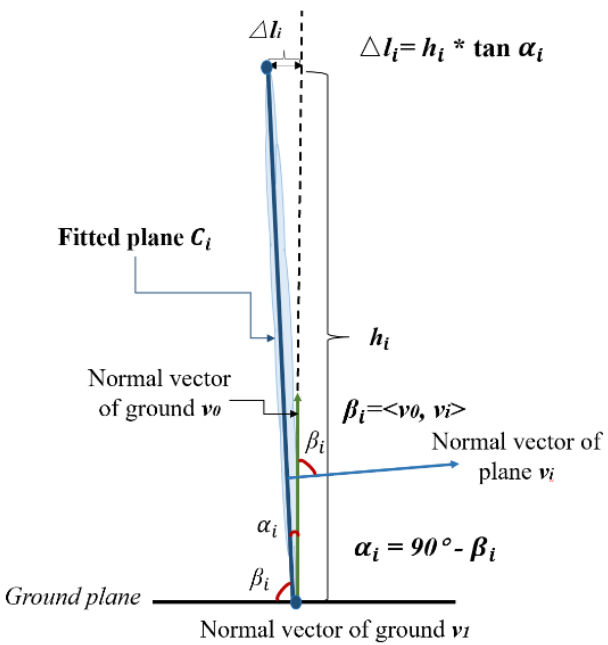

Figure 6. Vertical deviation computation.

The vertical deviation can be calculated applying basic trigonometry. The point cloud of each PWP is fitted to a planar surface in Section 4.2.2, and the normal vector of each PWP is also identified. The normal vector of the fitted plane is denoted as $v_{i}$ and the normal vector of the floor surface is $v_{0}$. Both are known after the using RANSAC. Angle $\beta_{0}$ between $v_{i}$ and $v_{0}$ represents the verticality of PWP; $\alpha_{i}$ represents the vertical angle deviation of the PWP. Vertical height $h_{i}$ of PWP is computed as the range of $\mathrm{z}$ values of the points in the fitted plane. The angle $\beta_{i}$ and vertical deviation $\Delta l_{i}$ are calculated based on Equations (1) and (2):

$$
\begin{gathered}
\beta_{i}=<v_{0}, v_{i}>=\arccos \frac{\left(x_{0} * x_{i}\right)+\left(y_{0} * y_{i}\right)+\left(z_{0} * z_{i}\right)}{\sqrt{x_{0}{ }^{2}+y_{0}{ }^{2}+z_{0}^{2}} * \sqrt{x_{i}{ }^{2}+y_{i}{ }^{2}+z_{i}^{2}}}, i=1,2, \ldots, n \\
\Delta l_{i}=h_{i} \times\left|\tan \left(90^{\circ}-\beta_{i}\right)\right|, h_{i}=\max \left[z_{i}\right]-\min \left[z_{i}\right], i=1,2, \ldots, n
\end{gathered}
$$


where $v_{0}\left(x_{0}, y_{0}, z_{0}\right)$ denotes the components of the normal vector of the floor surface, $v_{i}\left(x_{i}, y_{i}, z_{i}\right)$ denotes the components of the normal vector of $C_{i}$, and $n$ is the number of PWP.

The tolerance of verticality deviation of PWP is determined as $T_{v d}$, as given in Table 1. If $\Delta l_{i}$ is larger than $T_{v d}$, then the PWP needs to be rectified. Finally, all required attributes for IQC in the proposed method are listed in Table 3.

Table 3. Attributes in the proposed IQC method.

\begin{tabular}{cc}
\hline Quality Check & Attributes \\
\hline Horizontal & Horizontal alignment deviation $\left(d_{i j}\right)$ \\
Vertical & Deviation angle $\left(\beta_{i}\right)$ \\
& Height $\left(h_{i}\right)$ \\
& Vertical deviation $\left(\Delta l_{i}\right)$ \\
\hline
\end{tabular}

\section{Case Study Analysis}

After the development of the IQC process, a prefabricated construction project in China was used for determining the values of parameters used for the segmentation process, so that the method proposed could be validated and the parameters adopted for similar projects.

\subsection{Case Background}

The selected prefabricated project is located in Pudong district, Shanghai, China. The total floor area of this project is more than 14 ha with 15 high-rise residential buildings. The No. 11 building is a work-in-progress building and is selected for the case study in this research. It has sixteen floors, and each floor has four units. Each unit covers approximately $112-140 \mathrm{~m}^{2}$ floor area. The external walls, some parts of internal walls, and floor panels are prefabricated. Each floor has 24 external PWPs and 18 internal PWPs. The external PWPs were installed before internal PWPs. After installation of all PWPs for one floor area, the conventional IQC process was conducted on all panels individually. In this case study, the proposed laser scanning method is used for one-quarter of the total floor to check the panel installation, in comparison with the conventional manual method, as shown in Figure 1. The types of PWPs in this floor were covered in the selected part. As presented earlier, a Leica BLK 360 scanner is used. The layout of PWPs and scanning positions are given in Figure 7a. Seven PWPs are scanned simultaneously, as seen in Figure 7b, and information of PWPs is presented in Table 4 and Figure 8.

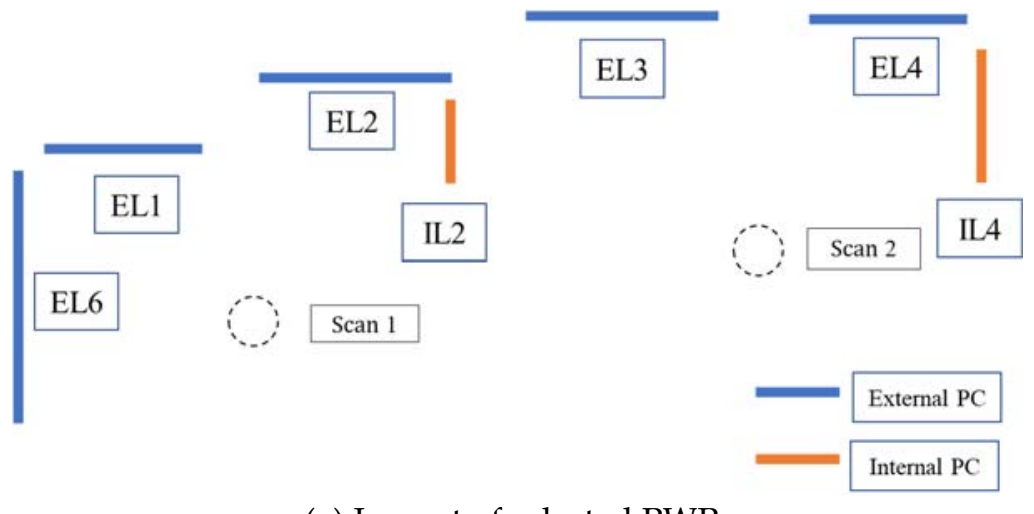

(a) Layout of selected PWPs

Figure 7. Cont. 


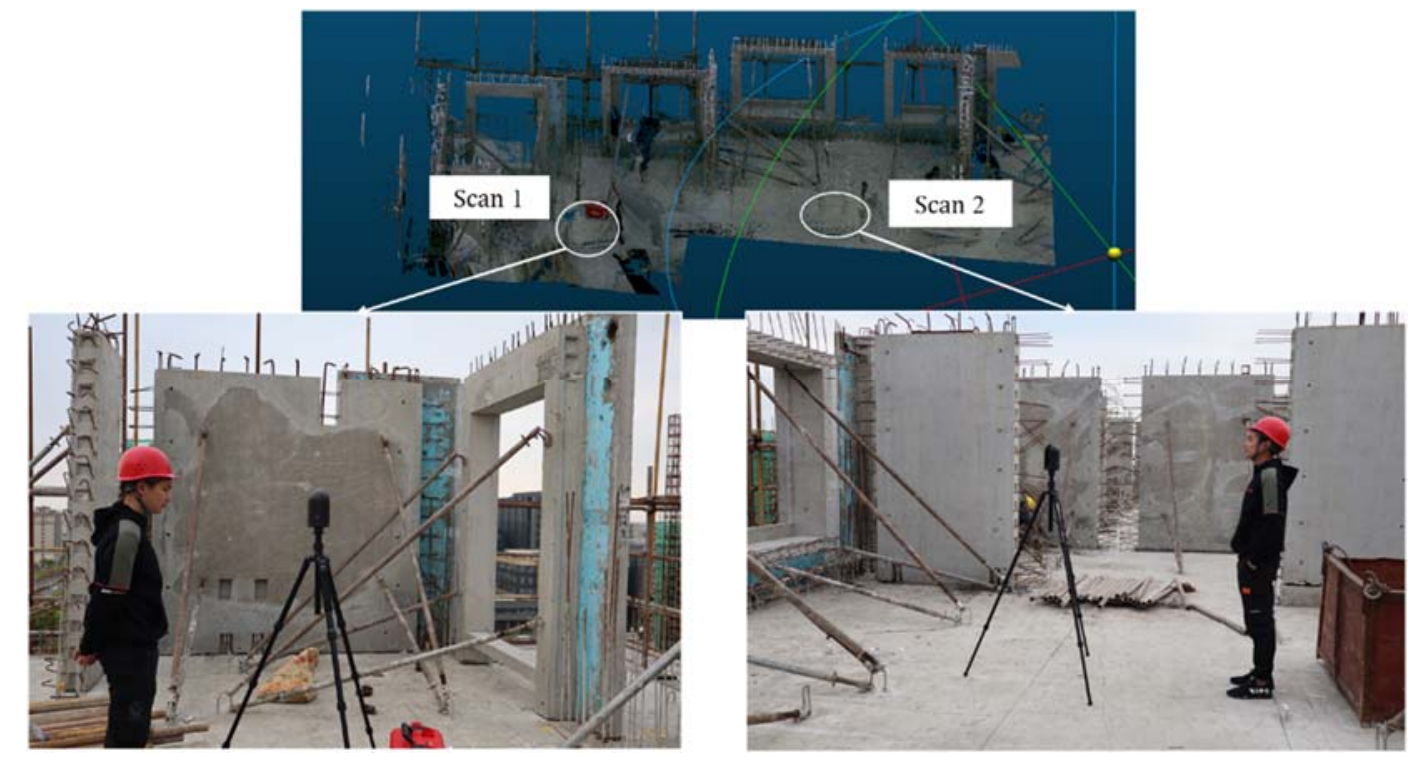

(b) Scanning position

Figure 7. Selected area of the case study.

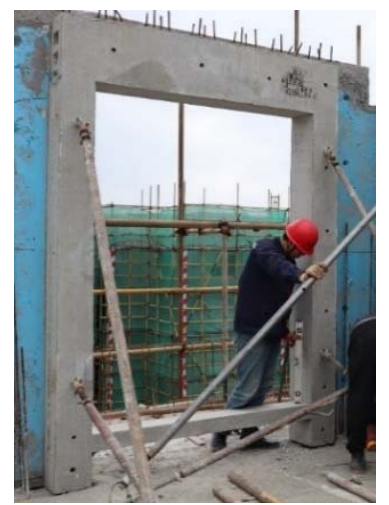

(a) Panel EL1

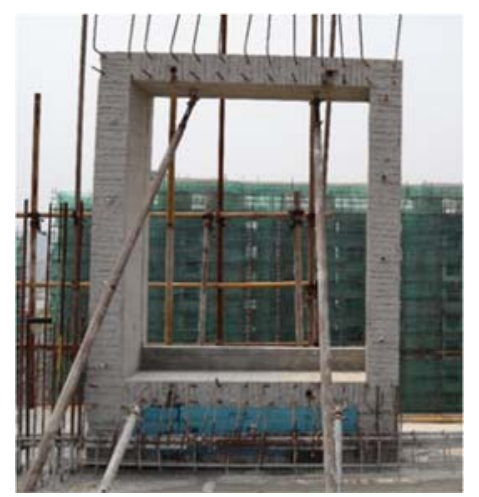

(d) Panel EL4

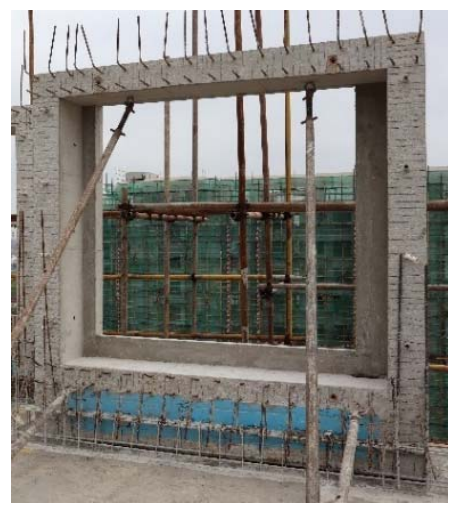

(b) Panel EL2

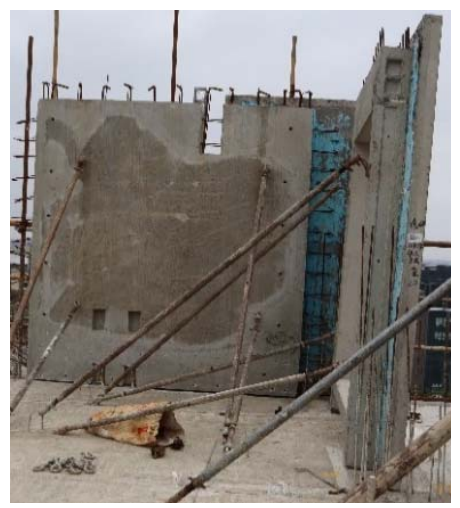

(e) Panel EL6

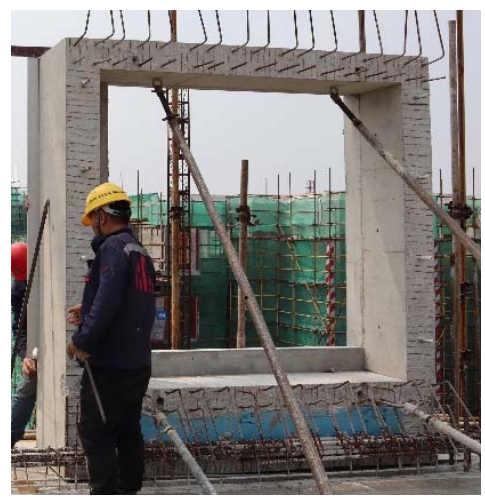

(c) Panel EL3

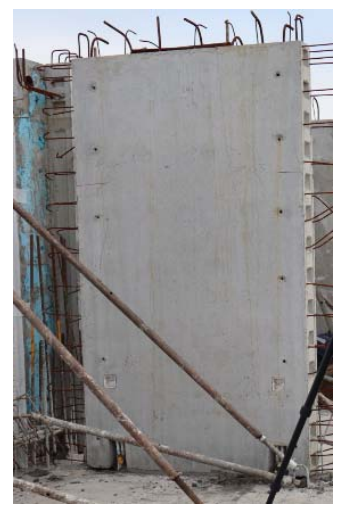

(f) Panel IL2, IL4

Figure 8. Images of internal (IL) PWPs and external (EL) PWPs. 
Table 4. The types of information for the scanned PWPs.

\begin{tabular}{cccc}
\hline Number of PWPs & PWP Type & PWP Shape & Type ID \\
\hline & & Figure 8a & EL1 \\
4 & Bay window panel & Figure 8b & EL2 \\
& & Figure 8c & EL3 \\
& & Figure 8d & EL4 \\
\hline 1 & External panel & Figure 8e & EL6 \\
2 & Internal panel & Figure 8f & IL2, IL4 \\
\hline
\end{tabular}

Figure $7 \mathrm{~b}$ shows the scanning process; the green circles are the places where the scanner was positioned. Two scans were used for the test PWPs. The point cloud co-registration was performed using the commercial Leica Cyclone software, along with manually cropping out the surrounding environment. The points of surrounding environment were removed to avoid unnecessary data processing with these points, as they were not used in the quality check process. Manual cropping of the surrounding environment usually required about 1 or $2 \mathrm{~min}$. Finally, a total of 10,226,246 points were used in the validation tests.

\subsection{Determination of Segmentation Parameters}

As mentioned in Section 4.2.1, the suitable values of the five segmentation parameters $(K S, N N, M C, S T, C T)$ need to be determined for the test-use case. We performed many rounds of trial and error before determining suitable parameter values. The purpose of choosing suitable values of parameters is to avoid over-segmentation and undersegmentation [34]. The general guideline for tuning the values of $K S, N N$, and $S T$ is to increase the values of $K S, N N$, and $S T$ if the result is over-segmentation. If the result is under-segmentation, then the values of $K S, N N$, and $S T$ need to be decreased. The following paragraph presents the process for each parameter, considering that some parameters were already assigned suitable values. In the figures of segmentation results, segments are represented in different colors.

For $\mathrm{K}$ search $(K S)$, as discussed in Section 4.2.1, the smallest value proposed by Xiao et al. [57] is 15, the largest value proposed by Deschaud and Goulette [59] is 50, so 15 50 is used as a testing range of $K S$ in this research, and the interval is set as 5. The testing results are summarized in Table 5 and Figure 9, for $N N=25$ and $S T=5$. In Figure 9a, when $K S=15,25$, and 30, only internal panels, IL2, IL4, and EL6 of regular rectangular shape are segmented, and this is over-segmentation. Figure $9 \mathrm{~b}$ shows that, when $K S=35$, the point cloud is appropriately segmented. All PWPs are segmented clearly from the data set. In Figure 9c, when $K S=40,45$, although PWPs can be recognized from the point cloud, some extra points are also recognized for EL1 and EL4. The segments are not planar surfaces and this is under-segmentation. Using this case study analysis, it is suggested that $K S=35$ be used for similar cases.

Table 5. Segmentation results of different $K S$ values.

\begin{tabular}{ccc}
\hline KS & Status & Segmentation Result \\
\hline 15 & Over-segmentation & \\
25 & Over-segmentation & Figure 9a \\
30 & Over-segmentation & Figure 9b \\
\hline 35 & Suitable segmentation & Figure 9c \\
\hline 40 & Under-segmentation & \\
\hline 45 & Under-segmentation & \\
\hline
\end{tabular}



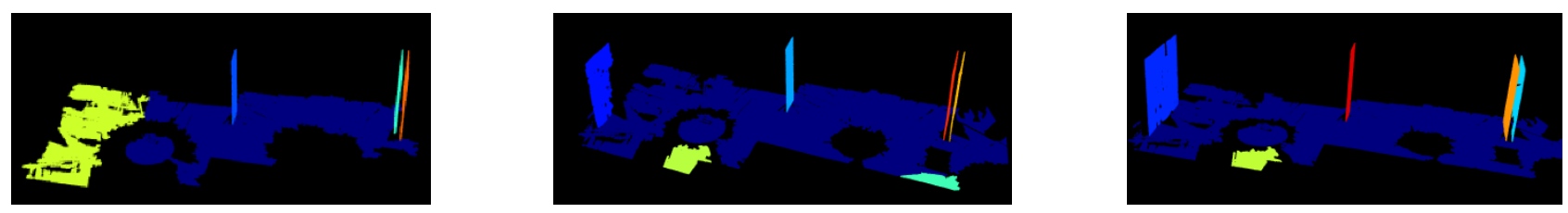

(a) Over-segmentation ( $K S=15, K S=25, K S=30$ ) (from left to right)

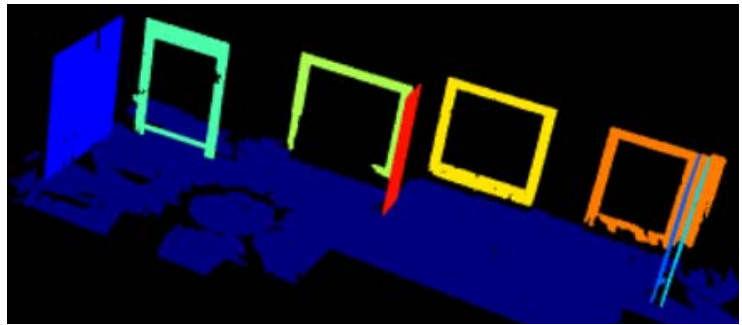

(b) Suitable segmentation $(K S=35)$
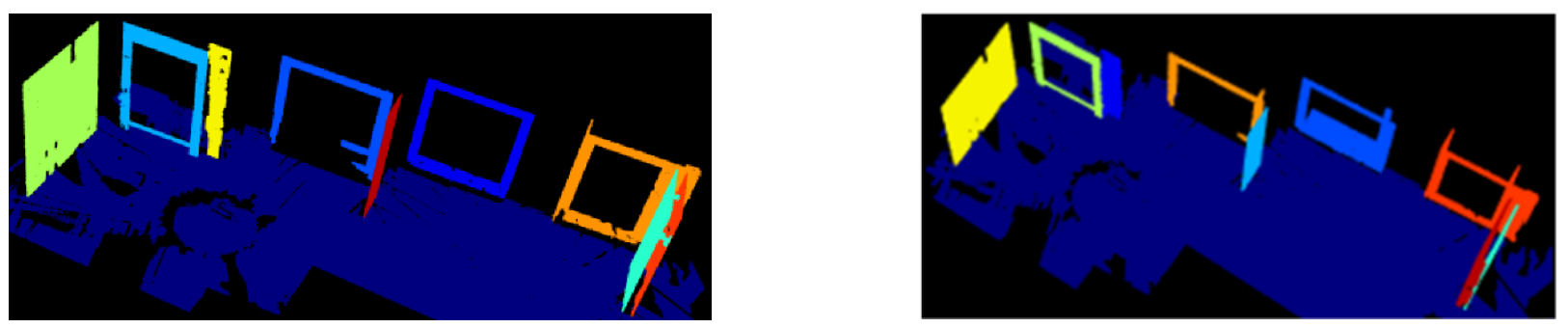

(c) Under-segmentation ( $K S=40, K S=45)$ (from left to right)

Figure 9. Segmentation results for different $K S$ values.

The determination of the suitable value of $N N$ is similar to that of $K S$. As $N N$ and $K S$ adopt the same method for finding neighbor points, the testing range of $N N$ is $15 \sim 50$ as well. The segmentation results are given in Table 6 and Figure $10(K S=35$ and ST =5). When NN is set as 15 and 20, only IL2, IL4, and EL6 are recognized, as seen in Figure 10a, and this is over-segmentation. When $N N$ is set as 35 and 40, Figure 10c shows many extra points are connected with EL1, EL3, and EL4 after segmentation. These segments of PWPs are not planer surfaces, and this is under-segmentation. While NN is set 25 and 30, the PWPs can be appropriately segmented, as shown in Figure 10b. Therefore, they are suggested as suitable $N N$ values. This study uses $N N=25$.

Table 6. Segmentation results of different $N N$ values.

\begin{tabular}{ccc}
\hline NN & Status & Segmentation Result \\
\hline 15 & Over-segmentation & Figure 10a \\
20 & Over-segmentation & Figure 10b \\
\hline 25 & Suitable segmentation & Fitable segmentation \\
30 & Under-segmentation & Figure 10c \\
\hline 35 & Under-segmentation & \\
\hline
\end{tabular}



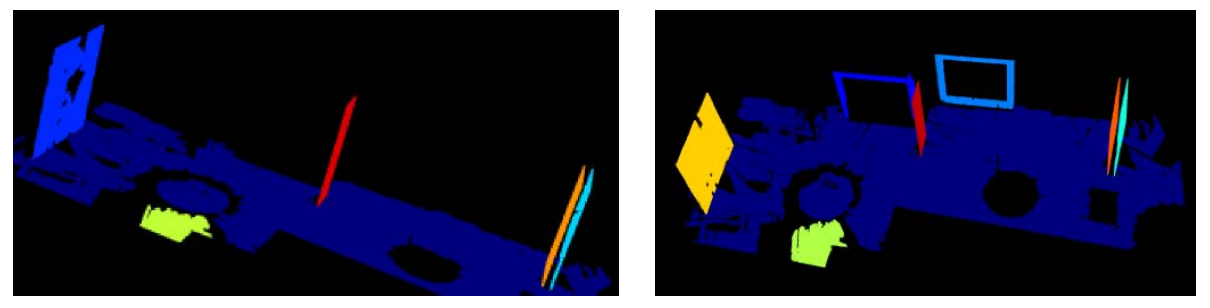

(a) Over-segmentation $(N N=15, N N=20)$ (from left to right)
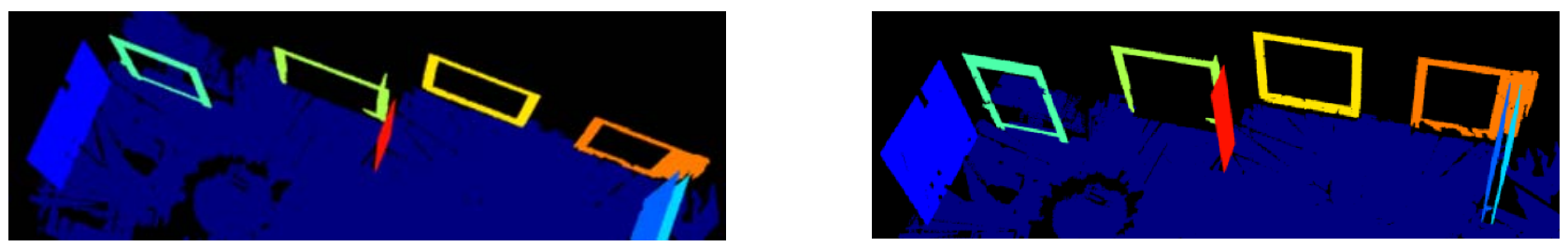

(b) Suitable segmentation ( $N N=25, N N=30)$ (from left to right)
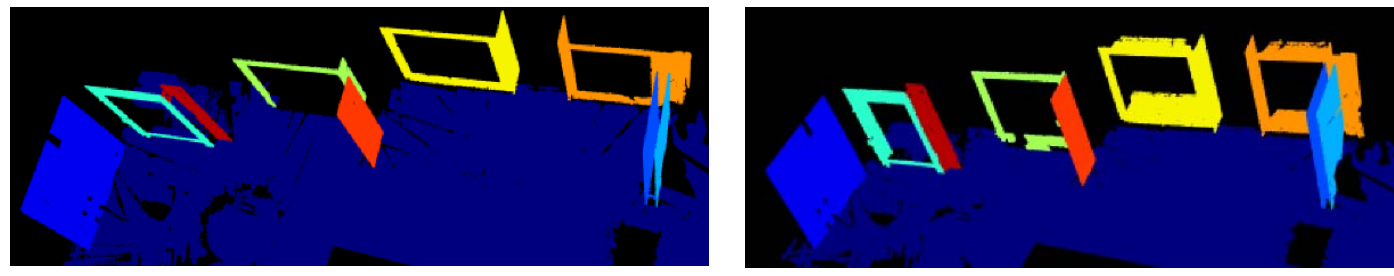

(c) Under-segmentation ( $N N=35, N N=40)$ (from left to right)

Figure 10. Segmentation results of different $N N$ values.

Smoothness threshold $\theta_{S}(S T)$, as mentioned in Section 4.2.1 and given a value of 10, could be a relatively large value for $\theta_{S}$ [34]. Thus, the thresholding test of $\theta_{S}$ is started from 1 to 10 , when $K S=35$ and $N N=25$. To quickly identify the suitable value and reduce testing times, first the middle value $\theta_{S}=5$ is tested. When $\theta_{S}$ is smaller than $5\left(\theta_{S}=4\right)$, the data are over-segmentation, as seen in Figure 11a. When $\theta_{S}$ is larger than $5\left(\theta_{S}=6\right)$, it is under-segmentation, as seen in Figure 11c. Thus, 5 is the suitable value for $\theta_{S}$ (Figure 11b).

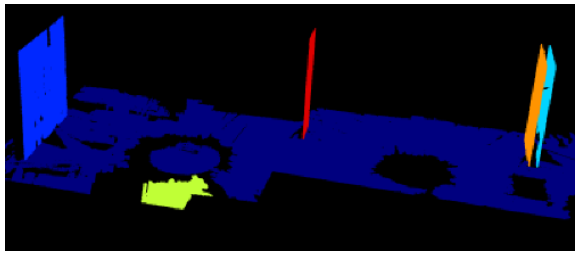

(a) Over-segmentation $\left(\theta_{S}=4\right)$

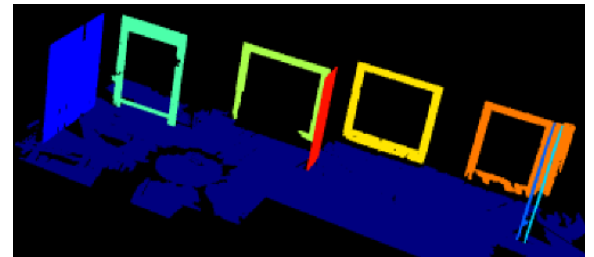

(b) Suitable segmentation $\left(\theta_{S}=5\right)$

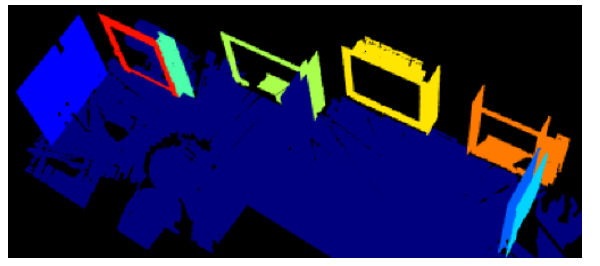

(c) Under-segmentation $\left(\theta_{S}=6\right)$

Figure 11. Segmentation results of different $\theta_{S}$ values.

After the tests, the suggested values of $C T\left(\gamma_{c}\right), M C, K S, N N$, and $S T\left(\theta_{S}\right)$ are summarized in Table 7. At this time, all the PWPs and floor surface in the case data can be identified after segmentation, and there are no other unnecessary segments. These suggested values can be adopted in the installation quality check-up processes for similar residential building projects using the same scanner. Since PWPs are widely used in prefabricated residential buildings, the values suggested can be used in many other cases. There may be variations in the shape and size of PWPs used in different projects, but the same values of these parameters can be used for the same type of laser scanners. When different laser scanners are used, these suggested parameter values provide a good estimate range, which can save time and effort in determining the suitable values for these scanners. Then, 
the RANSAC algorithm is used to fit the plane and remove outliers. Finally, normal vectors $v_{i}$ of each PWP are computed and used for checking the verticality of the installation of the wall panels.

Table 7. Suggested values of region growing segmentation parameters.

\begin{tabular}{cc}
\hline Parameter & Suggested Values \\
\hline$C T\left(\gamma_{c}\right)$ & 1 \\
$M C$ & 90,000 \\
$K S$ & 35 \\
$N N$ & 25 \\
$S T\left(\theta_{S}\right)$ & 5 \\
\hline
\end{tabular}

\subsection{IQC Results and Validation by Conventional Method}

The IQC process was conducted using the approach presented in Section 4.3. To validate the quality check results of the proposed method, a conventional method of IQC was conducted at the same time as the laser scanning. This was carried out by the manual check (steps 5 and 6 as shown in Figure 1). The validation results demonstrated that the proposed laser scanning method could correctly identify the PWPs need to be rectified. The IQC results of the manual check and proposed method are given in Table 8. This table includes the horizontal alignment deviation, vertical deviation, and the panels need to be rectified based on the check results of horizontal and vertical deviation.

Table 8. Results of proposed IQC method using laser scanning and manual check.

\begin{tabular}{|c|c|c|c|c|c|c|c|c|c|c|}
\hline \multirow{3}{*}{ PWP } & \multicolumn{4}{|c|}{ Horizontal Alignment Deviation } & \multicolumn{4}{|c|}{ Vertical Deviation } & \multirow{2}{*}{\multicolumn{2}{|c|}{$\begin{array}{c}\text { Panel Needs to Be Rectified } \\
\text { Based on Both Horizontal } \\
\text { and Vertical Check }\end{array}$}} \\
\hline & \multicolumn{2}{|c|}{$d_{i j}(\mathrm{~mm})$} & \multicolumn{2}{|c|}{ Result } & \multicolumn{2}{|c|}{$\Delta l_{i}(\mathrm{~mm})$} & \multicolumn{2}{|c|}{ Result } & & \\
\hline & $\begin{array}{c}\text { IQC } \\
\text { Method }\end{array}$ & $\begin{array}{c}\text { Manual } \\
\text { Check }\end{array}$ & $\begin{array}{c}\text { IQC } \\
\text { Method }\end{array}$ & $\begin{array}{c}\text { Manual } \\
\text { Check }\end{array}$ & $\begin{array}{c}\text { IQC } \\
\text { Method }\end{array}$ & $\begin{array}{c}\text { Manual } \\
\text { Check }\end{array}$ & $\begin{array}{c}\text { IQC } \\
\text { Method }\end{array}$ & $\begin{array}{c}\text { Manual } \\
\text { Check }\end{array}$ & $\begin{array}{c}\text { IQC } \\
\text { Method }\end{array}$ & Manual Check \\
\hline EL1 & & & & & 3.793 & 3.8 & $\sqrt{ }$ & $\sqrt{ }$ & & \\
\hline EL2 & & & & & 1.672 & 4.0 & $\sqrt{ }$ & $\sqrt{ }$ & & \\
\hline EL3 & $d_{34}$ & & $x$ & $x$ & 4.537 & 3.0 & $\sqrt{ }$ & $\sqrt{ }$ & $x$ & $x$ \\
\hline EL4 & $=6.719$ & $d=5.2$ & $\times$ & $x$ & 0.564 & 3.0 & $\sqrt{ }$ & $\sqrt{ }$ & $x$ & $x$ \\
\hline EL6 & & & & & 5.597 & 5.9 & $x$ & $\times$ & $\times$ & $x$ \\
\hline IL2 & & & & & 1.479 & 2.5 & $\sqrt{ }$ & $\sqrt{ }$ & & \\
\hline IL4 & & & & & 1.269 & 2.2 & $\sqrt{ }$ & $\sqrt{ }$ & & \\
\hline
\end{tabular}

Note: PWP = prefabricated wall panel, EL $=$ external wall panel, $\mathrm{IL}=$ internal wall panel, $\sqrt{ }=$ quality check passed, $\times=$ rectification required.

The results of horizontal alignment check are given in Table 8. Based on design requirements and design drawings, the bay window panel EL3 and panel EL4 need to be installed horizontally aligned, as seen in Figure 7a. Therefore, a quality check of horizontal alignment needs to be conducted on these two PWPs. According to the check result of the proposed laser scanning method, the relative horizontal deviation between panels EL3 and EL4 are computed as $6.716 \mathrm{~mm}$, which is larger than horizontal alignment deviation threshold $\left(T_{h d}=5 \mathrm{~mm}\right)$ as given in Section 3. Therefore, the IQC method indicates the installation of EL3 and EL4 do not satisfy the quality requirement. At the same time, their horizontal alignment deviation obtained by manual check is $5.2 \mathrm{~mm}$. The manual check indicates the panels EL3 and EL4 are not aligned and need to be rectified. Therefore, the horizontal alignment check of the proposed method matched with the manual check.

The check results of the verticality are also given in Table 8. The vertical deviation of panel EL6 is $5.597 \mathrm{~mm}$ according to the proposed laser scanning method, which is higher than the quality check requirement of verticality $\left(T_{v d}=5 \mathrm{~mm}\right)$ as presented in Section 3 . Thus, panel EL6 needs rectification. Panels EL2, EL3, and EL4 passed the vertical quality check, while their deviation $\Delta l_{i}$ of IQC method is drastically different from the manual check method. This is because there are many rebar connected on the bottom area of panels 
EL2, EL3, and EL4. The tuning of segmentation parameters might not be able to segment panels apart from rebar, which causes errors in the computation of verticality. According to the manual check, the vertical deviation of panel EL6 is $5.9 \mathrm{~mm}$. The manual check shows that panel EL6 needs rectification. Therefore, the verticality check results of the proposed method and manual check are also consistent.

After the quality check of horizontal alignment and verticality, resulting data for the panels that need to be rectified are presented in Table 8. If one of the horizontal alignment check or vertical check fails, the panel needs to be rectified. Therefore, panels EL3, EL4, and EL6 are identified for rectification. In conclusion, the proposed method could make IQC using laser scanning data and identify PWPs that need rectification correctly in this case study, which is the same as the results of the manual check.

The total time of using the laser scanning method included onsite data collection, preprocessing including data registration and cropping out the surrounding environment, and data processing of IQC. The data collection and preprocessing took around $10 \mathrm{~min}$. The total computation time of the data processing of IQC is shown in Table 9. The segmentation process was completed in approximately $140 \mathrm{~s}$, which is fast and efficient. The fitting process was finished in around $84 \mathrm{~s}$. The computation of IQC results for all PWPs took less than $4 \mathrm{~min}$. The total time using laser scanning for quality check was less than $14 \mathrm{~min}$.

Table 9. The computation time of the data processing of IQC.

\begin{tabular}{cc}
\hline Process & Computation Time (s) \\
\hline Region growing segmentation & 140 \\
RANSAC & 84 \\
Computation of $d_{i j}$ & 1 \\
Computation of $\beta_{i}$ & 1 \\
Computation of $\Delta l_{i}$ & 226 \\
Total & 226 \\
\hline
\end{tabular}

\subsection{Discussion}

This study uses the conventional manual quality check result to validate the laser scanning method as it is the current acceptable method used in practice. However, the manual check method is prone to many errors, such as reading errors, inaccurate placement of measuring tools, inaccuracy of the tools, etc. $[3,7,53]$. Theoretically, the laser scanning technology should have higher accuracy than the manual method and provide more reliable measuring results $[8,9]$. The accuracy of the results, however, depends on the scanning process and the applied processing algorithms. As the results show, the laser scanning quality check method and the conventional manual method identified the same panels that needed to be rectified. However, there are some differences in the values of horizontal and vertical deviations detected by these two methods.

Based on the experiments using these case data, it is found that some factors could influence the determination of segmentation parameters. First is the shape of PWP. The regular PWPs are more easily identified by the region growing algorithm, and larger range of parameters could be suitable for segmentation of regular shapes. For irregular PWPs, a much smaller range of parameters is suitable, especially the values for $K S, N N$, and ST. Second, the size of PWPs and point cloud density could also influence the value of parameters. For example, the $M C$ is determined by the PWP segment that has the smallest number of points, so changing either the size of PWP or point cloud density could affect the value of $M C$. The KS and NN could also be influenced by the point cloud density. When the point cloud density is higher, the normal estimation and neighbor point search for each point are more representative of local surface features under the same condition of $K S$ and $N N$ [54]. Therefore, for point cloud datasets of different density, the value of segmentation parameters needs to be adjusted. Some other factors, such as floor layout and the material of PWPs, might also influence the value of the segmentation parameters. 
For future exploration, there are some other approaches that can be used for segmentation and plane fitting. For example, segmentation based on voxel or mesh [33], or weighted regression techniques [65], etc., could be more promising approaches. The RANSAC is crucial to the verticality check. In addition to RANSAC, the Hough transform and least squares methods are alternative estimation techniques that may be useful for plane fitting [15,31]. Further study can be focused on the comparison among these approaches.

This case example adopted a single type of laser scanner BLK 360, which is easy to use on construction sites. This scanner was selected as it is widely available in Chinese construction companies due to its reasonable price; therefore, the proposed method can be conveniently adopted in practice. The operation of the BLK 360 scanner is quite simple, so it can be used by workers having no experience in surveying. The scanning time is fast, which is less than $3 \mathrm{~min}$ for one scan. The disadvantage of BLK 360 is that it has lower accuracy than other higher-end and more expensive scanners. In the next phase of the research, different types of scanners will be used to compare their effectiveness in quality check of installing prefabricated elements.

\section{Conclusions}

Installation quality check is a critical task in prefabricated construction, and currently mostly is still carried out by the manual method, which is slow and ineffective. Laser scanning technology can provide accurate geometric information of installed prefabricated elements and have great potential to be used in prefabrication quality check to replace the tedious manual method. This study demonstrates that laser scanning and manual approach identified the same panels for rectification, and this can be an indication that laser scanning can replace the manual approach. The laser scanning method is practical and more efficient than the manual approach for onsite quality check. The contribution of this method is demonstrated from two main aspects.

First, the proposed method is effective in correctly identifying the PWPs that needed to be rectified. This study considered selection of laser scanner, application scenario, and established procedures and quality check criteria of IQC for PWPs for construction sites. It used the widely available laser, BLK 360 , for data collection in consideration of its efficiency, accessibility, scanning range, accuracy, etc. The proposed method could carry out the IQC in a quick manner. Both the horizontal alignment and verticality of each PWP can be analyzed. Using the proposed laser scanning method, the quality check can be done in a much shorter time frame. For example, in the adopted case, the checking time by the current manual method was $2-3 \mathrm{~h}$ for one floor. The proposed method can complete scanning, transfer the data for analysis, and produce the outcome, all in less than $1 \mathrm{~h}$ for the same floor. If larger floor area and more PWPs are to be checked, the advantage of time saving could be more obvious.

Second, this study contributes to finding the appropriate parameter values for point cloud segmentation and classification, which is the critical step of the quality check process. The point cloud data collected from the construction site is complex with many objects, such as rebar, temporary support, and other construction materials. To accurately identify the PWPs from the point cloud data, appropriate parameter values need to be determined. In this study, the region growing algorithm is selected as it is easy to be adopted for plane segmentation. According to the actual case, which is a typical residential prefabrication construction project in China, suitable values of the segmentation parameters are determined based on a series of systematic tests. The suggested values of segmentation parameters can be used in similar projects.

In future work, different types of scanners and construction sites will be tested. If different scanners are used for data collection in the scanning process, the parameters may need to be further adjusted. In addition, the irregular shape of PWPs will influence the completeness of the segments; therefore, how to make a segmentation of various irregular panels can be further explored. This research provides a good reference on what parameter values can produce satisfactory segmentation in similar prefabrication construction projects. 
In future research, machine-learning techniques can be introduced to automate the test process and find the most appropriate parameter values for different scenarios.

As pointed out by some previous studies, laser scanning technology is one of the most promising technologies that can be applied in prefabricated construction, and could be combined with other technologies $[1,10,66]$. For example, to enhance the quality check process, the as-designed BIM model can be used as a reference for PWP identification, sensors can be used for locating and monitoring PWPs, and the Internet of Things could analyze and share the data collected by laser scanners in real time. Integrating these latest technologies with the proposed laser scanning method could further improve the efficiency of the onsite quality check.

Author Contributions: Conceptualization, M.W., C.C.W. and S.Z.; methodology, C.C.W., S.Z. and S.S.; software, M.W. and M.A.; validation, M.W., C.C.W. and S.Z.; formal analysis, C.C.W., S.Z. and S.S.; investigation, M.W.; resources, C.C.W., S.Z., S.S. and M.A.; data curation, M.W.; writing-original draft preparation, M.W.; writing - review and editing, C.C.W., S.Z. and S.S.; visualization, M.W.; supervision, C.C.W., S.S. and S.Z.; project administration, C.C.W.; funding acquisition, C.C.W., S.S. and S.Z. All authors have read and agreed to the published version of the manuscript.

Funding: This research was funded by the University of New South Wales (UNSW Sydney) Scientia PhD Scholarship Scheme.

Data Availability Statement: The data presented in this study are available on request from the corresponding author.

Conflicts of Interest: The authors declare no conflict of interest.

\section{References}

1. Wang, M.; Wang, C.C.; Sepasgozar, S.; Zlatanova, S. A Systematic Review of Digital Technology Adoption in Off-Site Construction: Current Status and Future Direction towards Industry 4.0. Buildings 2020, 10, 204. [CrossRef]

2. Kabirifar, K.; Mojtahedi, M.; Changxin Wang, C.; Tam, V.W.Y. Effective construction and demolition waste management assessment through waste management hierarchy; a case of Australian large construction companies. J. Clean Prod. 2021, 312, 127790. [CrossRef]

3. Wang, M.; Sun, J.; Du, H.; Wang, C. Relations between safety climate, awareness, and behavior in the chinese construction industry: A hierarchical linear investigation. Adv. Civ. Eng. 2018, 2018, 6580375. [CrossRef]

4. Kabirifar, K.; Mojtahedi, M.; Wang, C.C. A Systematic Review of Construction and Demolition Waste Management in Australia: Current Practices and Challenges. J. Clean Prod. 2020, 263, 121265. [CrossRef]

5. Li, Z.; Shen, G.Q.; Xue, X. Critical review of the research on the management of prefabricated construction. Habitat. Int. 2014, 43, 240-249. [CrossRef]

6. Orlowski, K.; Baduge, S.K.; Mendis, P. Prefabricated Composite Steel-Timber Stiffened Wall Systems with Post-Tensioning: Structural Analysis and Experimental Investigation under Vertical Axial Load. J. Struct. Eng. 2021, 147, 04020325. [CrossRef]

7. Sepasgozaar, S.M.E.; Shirowzhan, S.; Wang, C. A scanner technology acceptance model for construction projects. Procedia Eng. 2017, 180, 1237-1246. [CrossRef]

8. Czerniawski, T.; Nahangi, M.; Walbridge, S.; Haas, C. Automated Removal of Planar Clutter from 3D Point Clouds for Improving Industrial Object Recognition. In Proceedings of the International Symposium in Automation and Robotics in Construction, Banff, AB, Canada, 21-24 May 2019.

9. Golparvar-Fard, M.; Bohn, J.; Teizer, J.; Savarese, S.; Peña-Mora, F. Evaluation of image-based modeling and laser scanning accuracy for emerging automated performance monitoring techniques. Autom. Constr. 2011, 20, 1143-1155. [CrossRef]

10. Sepasgozar, S.; Wang, C.; Shirowzhan, S. Challenges and Opportunities for Implementation of Laser Scanners in Building Construction. In Proceedings of the ISARC 2016 33rd International Symposium on Automation and Robotics in Construction, Banff, AB, Canada, 21-24 May 2019; pp. 742-751.

11. Wang, Q.; Kim, M.K.; Sohn, H.; Cheng, J.C.P. Surface flatness and distortion inspection of precast concrete elements using laser scanning technology. Smart Struct. Syst. 2016, 18, 601-623. [CrossRef]

12. Bosché, F. Automated recognition of 3D CAD model objects in laser scans and calculation of as-built dimensions for dimensional compliance control in construction. Adv. Eng. Inform. 2010, 24, 107-118. [CrossRef]

13. Kim, M.-K.; Thedja, J.P.P.; Wang, Q. Automated dimensional quality assessment for formwork and rebar of reinforced concrete components using 3D point cloud data. Autom. Constr. 2020, 112, 103077. [CrossRef]

14. Hongjo, K.; Hyoungkwan, K.; Won, H.Y.; Hyeran, B. Detecting construction equipment using a region-based fully convolutional network and transfer learning. J. Comput. Civil. Eng. 2018, 32, 04017082. [CrossRef]

15. Wang, Q.; Kim, M.-K.; Cheng, J.C.P.; Sohn, H. Automated quality assessment of precast concrete elements with geometry irregularities using terrestrial laser scanning. Autom. Constr. 2016, 68, 170-182. [CrossRef] 
16. Liu, J.; Li, D.; Feng, L.; Liu, P.; Wu, W. Towards automatic segmentation and recognition of multiple precast concrete elements in outdoor laser scan data. Remote Sens. 2019, 11, 1383. [CrossRef]

17. Wang, Y.; Zhang, Z.; Qiu, Z. Automated house internal geometric quality inspection using laser scanning. In Proceedings of the 2015 International Conference on Intelligent Earth Observing and Applications, IEOAs 2015, Guilin, China, 9 December 2015.

18. Sanchez, B.; Rausch, C.; Haas, C.; Saari, R. A selective disassembly multi-objective optimization approach for adaptive reuse of building components. Resour. Conserv. Recycl. 2020, 154, 104605. [CrossRef]

19. Arashpour, M.; Heidarpour, A.; Akbar Nezhad, A.; Hosseinifard, Z.; Chileshe, N.; Hosseini, R. Performance-based control of variability and tolerance in off-site manufacture and assembly: Optimization of penalty on poor production quality. Constr. Manag. Econ. 2020, 38, 502-514. [CrossRef]

20. Da Rocha, C.; Tezel, A.; Talebi, S.; Koskela, L. Product modularity, tolerance management, and visual management: Potential synergies. In Proceedings of the 26th Annual Conference of the International Group for Lean Construction, Chennai, India, 16-22 July 2018; pp. 582-592.

21. Rausch, C.; Lu, R.; Talebi, S.; Haas, C. Deploying 3D scanning based geometric digital twins during fabrication and assembly in offsite manufacturing. Int. J. Constr. Manag. 2021, 1-14. [CrossRef]

22. Rausch, C.; Nahangi, M.; Haas, C.; West, J. Kinematics chain based dimensional variation analysis of construction assemblies using building information models and 3D point clouds. Autom. Constr. 2017, 75, 33-44. [CrossRef]

23. Bosché, F.; Guenet, E. Automating surface flatness control using terrestrial laser scanning and building information models. Autom. Constr. 2014, 44, 212-226. [CrossRef]

24. Li, D.; Liu, J.; Feng, L.; Zhou, Y.; Liu, P.; Chen, Y.F. Terrestrial laser scanning assisted flatness quality assessment for two different types of concrete surfaces. Measurement 2020, 154, 107436. [CrossRef]

25. Kim, M.-K.; Sohn, H.; Chang, C.-C. Automated dimensional quality assessment of precast concrete panels using terrestrial laser scanning. Autom. Constr. 2014, 45, 163-177. [CrossRef]

26. Guo, J.; Wang, Q.; Park, J.H. Geometric quality inspection of prefabricated MEP modules with 3D laser scanning. Autom. Constr. 2020, 111, 103053. [CrossRef]

27. Li, H.; Zhang, C.; Song, S.; Demirkesen, S.; Chang, R. Improving Tolerance Control on Modular Construction Project with 3D Laser Scanning and BIM: A Case Study of Removable Floodwall Project. Appl. Sci. 2020, 10, 8680. [CrossRef]

28. Grilli, E.; Menna, F.; Remondino, F. A review of point clouds segmentation and classification algorithms. Int. Arch. Photogramm. Remote. Sens. Spat. Inf. Sci. 2017, 42, 339. [CrossRef]

29. Biosca, J.M.; Lerma, J.L. Unsupervised robust planar segmentation of terrestrial laser scanner point clouds based on fuzzy clustering methods. ISPRS J. Photogramm. Remote Sens. 2008, 63, 84-98. [CrossRef]

30. Vo, A.V.; Truong-Hong, L.; Laefer, D.F.; Bertolotto, M. Octree-based region growing for point cloud segmentation. ISPRS J. Photogramm. Remote Sens. 2015, 104, 88-100. [CrossRef]

31. Bosché, F.; Ahmed, M.; Turkan, Y.; Haas, C.T.; Haas, R. The value of integrating Scan-to-BIM and Scan-vs-BIM techniques for construction monitoring using laser scanning and BIM: The case of cylindrical MEP components. Autom. Constr. 2015, 49, 201-213. [CrossRef]

32. Nikoohemat, S.; Diakité, A.A.; Zlatanova, S.; Vosselman, G. Indoor 3D reconstruction from point clouds for optimal routing in complex buildings to support disaster management. Autom. Constr. 2020, 113, 103109. [CrossRef]

33. Xu, Y.; Tuttas, S.; Hoegner, L.; Stilla, U. Voxel-based segmentation of 3D point clouds from construction sites using a probabilistic connectivity model. Pattern Recogn. Lett. 2018, 102, 67-74. [CrossRef]

34. Dong, Z.; Yang, B.; Hu, P.; Scherer, S. An efficient global energy optimization approach for robust 3D plane segmentation of point clouds. ISPRS J. Photogramm. Remote Sens. 2018, 137, 112-133. [CrossRef]

35. Vosselman, G.; Gorte, B.G.; Sithole, G.; Rabbani, T. Recognising structure in laser scanner point clouds. Inter. Arch. Photogramm. Remote Sens. Spat. Inf. Sci. 2003, 46, 33-38.

36. Xu, B.; Jiang, W.; Shan, J.; Zhang, J.; Li, L. Investigation on the Weighted RANSAC Approaches for Building Roof Plane Segmentation from LiDAR Point Clouds. Remote Sens. 2016, 8, 5. [CrossRef]

37. Wu, J.; Peng, L.; Li, J.; Zhou, X.; Zhong, J.; Wang, C.; Sun, J. Rapid safety monitoring and analysis of foundation pit construction using unmanned aerial vehicle images. Autom. Constr. 2021, 128, 103706. [CrossRef]

38. Martínez, J.; Rivera, F.F.; Cabaleiro, J.C.; Vilariño, D.L.; Pena, T.F.; David Miranda, B. A rule-based classification from a regiongrowing segmentation of airborne lidar. In Proceedings of the Image and Signal Processing for Remote Sensing XXII, Edinburgh, UK, 18 October 2016.

39. Filin, S.; Pfeifer, N. Segmentation of airborne laser scanning data using a slope adaptive neighborhood. ISPRS J. Photogramm. Remote Sens. 2006, 60, 71-80. [CrossRef]

40. Filin, S. Surface clustering from airborne laser scanning data. Int. Arch. Photogramm. Remote Sens. Spat. Inf. Sci. 2002, 34, 119-124.

41. Guo, J.; Yuan, L.; Wang, Q. Time and cost analysis of geometric quality assessment of structural columns based on 3D terrestrial laser scanning. Autom. Constr. 2020, 110, 103014. [CrossRef]

42. Jung, J.; Hong, S.; Jeong, S.; Kim, S.; Cho, H.; Hong, S.; Heo, J. Productive modeling for development of as-built BIM of existing indoor structures. Autom. Constr. 2014, 42, 68-77. [CrossRef]

43. Nguyen, T.A.; Nguyen, P.T.; Do, S.T. Application of BIM and 3D Laser Scanning for Quantity Management in Construction Projects. Adv. Civ. Eng. 2020, 2020, 8839923. [CrossRef] 
44. Sanhudo, L.; Ramos, N.M.M.; Martins, J.P.; Almeida, R.M.S.F.; Barreira, E.; Simões, M.L.; Cardoso, V. A framework for in-situ geometric data acquisition using laser scanning for BIM modelling. J. Build. Eng. 2020, 28, 101073. [CrossRef]

45. ACI Committee 533. Guide for Precast Concrete Wall Panels/Reported by ACI Committee 533. 2004. Available online: https:// www.academia.edu/39055132/ACI_533R_93_Guide_for_Precast_Concrete_Wall_Panels_Reported_by_ACI_Committee_533 (accessed on 16 June 2021).

46. Reinforced Concrete Design (in Accordance with AS 3600-2009). 2011. Available online: https://www.ccaa.com.au/imis_prod/ documents/INDUSTRY_GUIDE_T38_Reinforced_Concrete_Design_in_Accordance_with_AS3600.pdf (accessed on 12 July 2021).

47. AS3600-Concrete Structures. 2018. Available online: https://infostore.saiglobal.com/en-au/standards/as-3600-2018-98877_ saig_as_as_207930/(accessed on 12 July 2021).

48. Precast Concrete Handbook. 2009. Available online: https://nationalprecast.com.au/portfolio_page/precast-concretehandbook/ (accessed on 12 July 2021).

49. China Academy of Building Research. GB-50204-2015 Code for Acceptance of Construction Quality of Concrete Structures. 2015. Available online: http://www.jianbiaoku.com/webarbs/book/70535/1651683.shtml (accessed on 12 July 2021).

50. China Building Standards Design and Research Institute. Technical Specification for Precast Concrete Structures JGJ 1-2014. 2014. Available online: http:/ / www.mohurd.gov.cn/wjfb/202002/t20200221_244041.html (accessed on 12 July 2021).

51. Lin, Y.J.; Habib, A.; Bullock, D.; Prezzi, M. Application of High-Resolution Terrestrial Laser Scanning to Monitor the Performance of Mechanically Stabilized Earth Walls with Precast Concrete Panels. J. Perform. Constr. Facil. 2019, 33, 04019054. [CrossRef]

52. Stereva, K.; Postolovski, A.; Gospodinov, S. Control in the Process of the Building Construction by Means of Stationary Terrestrial Laser Scanning. In Proceedings of the IOP Conference Series: Earth and Environmental Science, Prague, Czech Republic, 7-11 September 2020; p. 012042.

53. Al-Rawabdeh, A.; Aldosari, M.; Bullock, D.; Habib, A. Mobile LiDAR for scalable monitoring of mechanically stabilized earthwalls with smooth panels. Appl. Sci. 2020, 10, 4480. [CrossRef]

54. Lari, Z.; Habib, A.; Kwak, E. An adaptive approach for segmentation of 3D laser point cloud. Int. Arch. Photogramm. Remote Sens. Spat. Inf. Sci. 2012, XXXVIII-5/W12, 103-108. [CrossRef]

55. Tóvári, D.; Pfeifer, N. Segmentation based robust interpolation-a new approach to laser data filtering. Int. Arch. Photogramm. Remote Sens. Spat. Inf. Sci. 2005, 36, 79-84.

56. Yang, B.; Dong, Z. A shape-based segmentation method for mobile laser scanning point clouds. ISPRS J. Photogramm. Remote Sens. 2013, 81, 19-30. [CrossRef]

57. Xiao, J.; Adler, B.; Zhang, J.; Zhang, H. Planar segment based three-dimensional point cloud registration in outdoor environments. J. Field Rob. 2013, 30, 552-582. [CrossRef]

58. Shao, J.; Zhang, W.; Shen, A.; Mellado, N.; Cai, S.; Luo, L.; Wang, N.; Yan, G.; Zhou, G. Seed point set-based building roof extraction from airborne LiDAR point clouds using a top-down strategy. Autom. Constr. 2021, 126, 103660. [CrossRef]

59. Deschaud, J.-E.; Goulette, F. A Fast and Accurate Plane Detection Algorithm for Large Noisy Point Clouds Using Filtered Normals and Voxel Growing. In Proceedings of the 3DPVT, Paris, France, 17 May 2010.

60. Oskouie, P.; Becerik-Gerber, B.; Soibelman, L. Automated measurement of highway retaining wall displacements using terrestrial laser scanners. Autom. Constr. 2016, 65, 86-101. [CrossRef]

61. Schaefer, A.; Vertens, J.; Buscher, D.; Burgard, W. A maximum likelihood approach to extract finite planes from 3-d laser scans. In Proceedings of the 2019 International Conference on Robotics and Automation, ICRA 2019, Montreal, QC, Canada, 20-24 May 2019; pp. 72-78.

62. Gilani, S.A.N.; Awrangjeb, M.; Lu, G. Segmentation of airborne point cloud data for automatic building roof extraction. GISci. Remote Sens. 2018, 55, 63-89. [CrossRef]

63. Duan, Y.; Yang, C.; Li, H. Low-complexity adaptive radius outlier removal filter based on PCA for lidar point cloud denoising. Appl. Opt. 2021, 60, E1-E7. [CrossRef] [PubMed]

64. Imre, E.; Hilton, A. Order statistics of RANSAC and their practical application. Int. J. Comput. Vis. 2015, 111, 276-297. [CrossRef]

65. Nurunnabi, A.; West, G.; Belton, D. Robust Locally Weighted Regression Techniques for Ground Surface Points Filtering in Mobile Laser Scanning Three Dimensional Point Cloud Data. IEEE Trans. Geosci. Remote Sens. 2016, 54, 2181-2193. [CrossRef]

66. Shirowzhan, S.; Sepasgozar, S.M.E.; Zaini, I.; Wang, C. An integrated GIS and Wi-Fi based Locating system for improving construction labor communications. In Proceedings of the 34th International Symposium on Automation and Robotics in Construction, ISARC 2017, Taipei, Taiwan, 28 June-1 July 2017; pp. 1052-1059. 